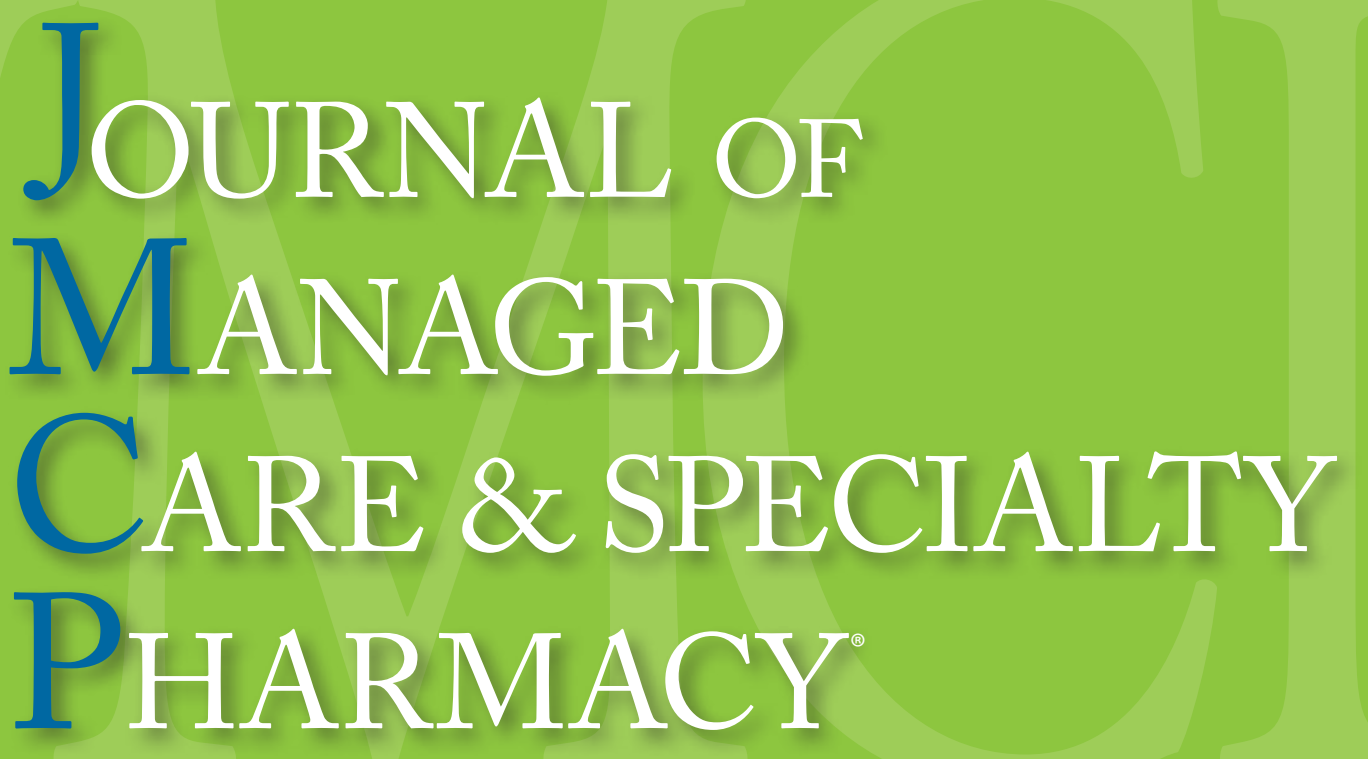

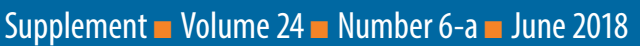

\title{
Viscosupplementation for Osteoarthritis of the Knee: A Key Opinion Leader Panel Discussion
}

Jack Bert, MD; Jim Kenney, RPh, MBA; Nicholas A. Sgaglione, MD; Scott McClelland, PharmD, RPh, CHIE;

Robert Brophy, MD; John Toth, RPh; Joseph Ruane, DO; Yousaf Ali, MD, FACR; Sheila Arquette, RPh;

Vinod Dasa, MD; and Maria Lopes, MD 


\section{JMCP}

\section{Publisher}

Susan A. Cantrell, RPh, CAE

Chief Executive Officer

Academy of Managed Care Pharmacy

\section{Editor-in-Chief}

Laura E. Happe, PharmD, MPH

727.488.2700, lhappe@jmcp.org

\section{Assistant Editor}

Donald G. Klepser, PhD, MBA

University of Nebraska Medical Center

Omaha, NE

\section{Assistant Editor}

Robert P. Navarro, PharmD

University of Florida College of Pharmacy

Gainesville, FL

\section{Assistant Editor}

Karen L. Rascati, PhD

University of Texas College of Pharmacy

Austin, TX

\section{Managing Editor}

Jennifer A. Booker

703.317.0725, jmcpreview@amcp.org

\section{Production Editor}

Carol Blumentritt

602.616.7249, cblumentritt@amcp.org

\section{Graphic Designer}

Margie C. Hunter

703.297.9319,mhunter@amcp.org

\section{Account Manager}

Bryan Bonder

American Medical Communications

610.715.4384,Bbonder@americanmedicalcomm.com

Maria Sercia

American Medical Communications

908.216.1548,MSercia@americanmedicalcomm.com

This supplement to the Journal of Managed Care \& Specialty Pharmacy (ISSN 1944-706X) is a publication of the Academy of Managed Care Pharmacy, 675 North Washington Street, Suite 220, Alexandria, VA 22314; 703.684.2600; 703.684.2651 (fax)

Copyright (C) 2018, Academy of Managed Care Pharmacy. All rights reserved. No part of this publication may be reproduced or transmitted in any form or by any means, electronic or mechanical, without written permission from the Academy of Managed Care Pharmacy.

POSTMASTER: Send address changes to JMCP,

675 North Washington Street, Suite 220, Alexandria, VA 22314.

\section{Supplement Policy Statement}

\section{Standards for Supplements to the}

Journal of Managed Care \& Specialty Pharmacy Supplements to the Journal of Managed Care \& Specialty Pharmacy (JMCP) are intended to support medical education and research in areas of clinical practice, health care quality improvement, or efficient administration and delivery of health benefits. The following standards are applied to all JMCP supplements to ensure quality and assist readers in evaluating potential bias and determining alternate explanations for findings and results

1. Disclose the principal sources of funding in a manner that permits easy recognition by the reader.

2. Disclose the existence of all potential conflicts of interest among supplement contributors, including financial or personal bias.

3. Describe all drugs by generic name unless the use of the brand name is necessary to reduce the opportunity for confusion among readers.

4. Identify any off-label (unapproved) use by drug name and specific off-label indication

5. Strive to report subjects of current interest to managed care pharmacists and other managed care professionals.

6. Seek and publish content that does not duplicate content in the Journal of Managed Care E Specialty Pharmacy.

7. Subject all supplements to expert peer review.
Jack Bert, MD, is a Mayo Clinic-trained, board-certified orthopedic surgeon. He serves as adjunct Clinical Professor at the University of Minnesota School of Medicine. He is a member of the Board of Directors of the Retired NFL Player's Association, founder of the Cartilage Restoration Center of Minnesota, Medical Director of Minnesota Bone and Joint Specialists, and former Executive Advisor for the Arthroscopy Association of North America (AANA) Board of Directors. He is the former President of AANA and a past member of the Board of Directors of the AAOS Orthopedic Learning Center and is the current chair of the American Academy of Orthopedic Surgeons (AAOS) Annual Meeting Practice Management Committee. He teaches courses annually on the treatment of cartilage lesions of the knee for the AAOS and AANA. He has authored over 72 articles and 18 book chapters for peer-reviewed orthopedic journals and speaks nationally and internationally on topics related to osteoarthritis of the knee.

Jim Kenney, RPh, MBA, is Manager of Specialty and Pharmacy Contracts at Harvard Pilgrim Healthcare. With 36 years of experience in managed care pharmacy, he has overseen contract management for a $\$ 1$ billion pharmacy budget. He serves as preceptor for the Massachusetts College of Pharmacy and Health Sciences, on the Board of Directors for the Academy of Managed Care Pharmacy, and as a member of the Massachusetts Pharmacists Association Legislative Committee.

Nicholas Sgaglione, MD, is Chair of the North Shore - Long Island Jewish Medical Center - Northwell Health System Department of Orthopedic Surgery and Professor at the Zucker School of Medicine at Hofstra/Northwell. He serves as Senior Vice President of Orthopaedics for the Northwell Health System and Executive Director of the Orthopaedic Institute. Dr. Sgaglione has been in clinical practice for 29 years. He was elected as President of the Arthroscopy Association of North America for 2012-2013 and has served on its Board of Directors since 2008, as well as being elected by his peers to the American Orthopaedic Association in 2006. He is an active member of the American Academy of Orthopaedic Surgeons, American Orthopaedic Society of Sports Medicine, International Cartilage Regeneration Society, and New York Society of Orthopaedic Surgeons. Dr. Sgaglione serves as the current chairman of the Arthroscopy Journal Board of Trustees. He is on the editorial board of several medical journals, is the editor of 3 orthopedic textbooks, and has more than 80 published articles and book chapters on knee, shoulder, ankle and cartilage surgery.

Scott McClelland, PharmD, RPh, CHIE, is Vice President of Commercial and Specialty Pharmacy Programs for Florida Blue. He is responsible for leading the internal pharmacy team and for the oversight and development of clinical and operational strategy for the traditional, specialty, and medical pharmacy areas. He has over 20 years of experience as a clinical pharmacist, specializing in critical care hospital-based medicine and pharmacy benefit management. He is a member of the Academy of Managed Care Pharmacy, America's Health Insurance Plans, and American Society of Health-System Pharmacists and has served as Chair of the Blue Cross and Blue Shield National Council of Physician and Pharmacist Executives Association.

Robert Brophy, MD, is Associate Professor in the Department of Orthopaedic Surgery at Washington University School of Medicine in St. Louis. He serves on the Board of Directors for the America Academy of Orthopaedic Surgeons and has authored over 175 peer-reviewed publications.

John Toth, RPh, is Manager of Pharmacy Program Development at Yale Health and has previously served as Pharmacy Operations Manager.

Joseph Ruane, DO, is Medical Director of McConnell Spine, Sport, and Joint Center; Head Team Physician for the NHL Columbus Blue Jackets; and Co-Founder of OhioHealth Sports Medicine Institute. He has over 20 years of experience in private practice primary care sports medicine. He serves as Clinical Assistant Professor of Sports Medicine at the Ohio University College of Osteopathic Medicine and serves on the Editorial Board of Practical Pain Management.

Yousaf Ali, MD, FACR, is Vice Chair of Faculty Affairs at the Samuel Bronfman Department of Medicine and Associate Professor of Medicine in the Division of Rheumatology at the Icahn School of Medicine at Mount Sinai.

Sheila Arquette, RPh, is Director of Pharmacy Services for Independent Health and serves as Co-Chair of the National Association of Specialty Pharmacy (NASP) Government Affairs Committee, was elected to the NASP Board of Directors, and received the NASP Distinguished Service Award in September 2016.

Vinod Dasa, MD, is Vice Chair of Academic Affairs for the Department of Orthopedic Surgery at Louisiana State University Health Sciences Center and Medical Staff President at the Oschner Kenner Medical Center. Dr. Dasa also serves as Chief Medical Officer of Vector Medical and as adjunct faculty at Touro University Nevada College of Osteopathic Medicine and Irvin Cahen MD Endowed Research Chair in Orthopedic Surgery.

Maria Lopes, MD, is Chief Medical Officer of Magellan Rx Management. She previously served as Chief Medical Officer of GHI/EmblemHealth and AMCHealth, as well as Chief Medical Director of Horizon Blue Cross/Blue Shield of New Jersey. 


\section{Table of Contents}

\section{Viscosupplementation for Osteoarthritis of the Knee: \\ A Key Opinion Leader Panel Discussion}

Jack Bert, MD; Jim Kenney, RPh, MBA; Nicholas A. Sgaglione, MD; Scott McClelland, PharmD, RPh, CHIE; Robert Brophy, MD; John Toth, RPh; Joseph Ruane, DO; Yousaf Ali, MD, FACR; Sheila Arquette, RPh;

Vinod Dasa, MD; and Maria Lopes, MD

S2 Background

S2 Epidemiology

S2 Patient Burden

S2 Diagnosis and Treatment Goals

S3 Treatment Considerations in the Management of OAK, Including Use of HA Injections

S3 Gaps in Care/Guidelines

S3 Overview of HA Injections and Role in Treatment

S4 Panel Insights and Recommendations

S6 Further Needs and Considerations 


\title{
Viscosupplementation for Osteoarthritis of the Knee: A Key Opinion Leader Panel Discussion
}

\author{
Jack Bert, MD; Jim Kenney, RPh, MBA; Nicholas A. Sgaglione, MD; \\ Scott McClelland, PharmD, RPh, CHIE; Robert Brophy, MD; John Toth, RPh; Joseph Ruane, DO; \\ Yousaf Ali, MD, FACR; Sheila Arquette, RPh; Vinod Dasa, MD; and Maria Lopes, MD
}

\begin{abstract}
SUMMARY
With a sharp rise in the prevalence of osteoarthritis of the knee (OAK) in a younger population, new management strategies are needed to preserve mobility, improve patients' quality of life, and reduce the effects of potential disease-related comorbidities. Viscosupplementation with the use of hyaluronic acid $(\mathrm{HA})$ injection is a treatment option for OAK that can provide lubrication and elastic shock absorption, leading to potential pain relief, improved function, and reduced stiffness. A key opinion leader (KOL) panel discussion was held December 3, 2016, with the objective of sharing opinions, ideas, information, and trends regarding OAK and the potential treatment and management offered by viscosupplementation. The panel concluded that viscosupplementation with HA injections presents a viable, cost-effective, and safe alternative for the treatment of OAK.
\end{abstract}

J Manag Care Spec Pharm. 2018;24(6-a):S2-S7

Copyright $\odot 2018$, Academy of Managed Care Pharmacy. All rights reserved.

A live key opinion leader (KOL) panel discussion was held December 3, 2016, in New York City, New York. In attendance were the following 11 KOLs with varying titles and specialties in the field: 4 pharmacists, 3 orthopedic surgeons in clinical practice, 1 rheumatologist, 1 medical officer for a pharmacy benefits manager, 1 professor of orthopedic surgery, and 1 sports medicine physician. With a sharp rise in the prevalence of osteoarthritis of the knee (OAK) in a younger population, new management strategies are needed to preserve mobility, improve patients' quality of life, and reduce the effects of potential disease-related comorbidities. Viscosupplementation with the use of hyaluronic acid (HA) injection is a treatment option for OAK that can provide lubrication and elastic shock absorption, leading to potential pain relief, improved function, and reduced stiffness. The objective of this panel was to share opinions, ideas, information, and trends regarding OAK and the potential treatment and management offered by viscosupplementation. The panel concluded that viscosupplementation with HA injections presents a viable, cost-effective, and safe alternative for the treatment of OAK.

\section{Background}

OAK, a degenerative form of arthritis, is the most common type of arthritis in the knee, affecting 14 million individuals in the United States. ${ }^{1}$ OAK is associated with degradation of the cartilage in the knee joint space, which leads to symptoms such as pain, stiffness, and crepitus. ${ }^{2}$ The condition can be mechanically driven and age-dependent, but it is biochemically mediated. ${ }^{3}$ Factors such as obesity, mechanical axis malalignment, and macrotrauma may lead to biophysical changes that ultimately result in the degradation of articular cartilage. ${ }^{3}$ In patients without osteoarthritis, HA aids in the lubrication and cushioning of the synovial joint and may play a role in reducing toxic catabolic oxidative synovial chemokines and potentially improve the viscosity of synovial fluid. ${ }^{4-6}$ In osteoarthritis, however, HA is observed to have a reduced molecular weight and lower concentration, which results in a decreased viscosity and elasticity of the synovial fluid, potentially contributing to the pain, stiffness, and loss of mobility. ${ }^{6,7}$ Viscosupplementation with $\mathrm{HA}$ is a procedure during which $\mathrm{HA}$ is injected into the knee joint, which has been shown to provide lubrication and elastic shock absorption, leading to pain relief, improved function, and reduced stiffness. ${ }^{4-7}$ However, HA injections are typically reserved for clinical cases in which patients are no longer able to manage their condition with traditional treatments such as physical therapy and nonsteroidal anti-inflammatory drugs (NSAIDs). ${ }^{\top}$

\section{Epidemiology}

Although OAK has generally been associated with advanced age, the patient demographics of OAK are changing, with a sharp rise in prevalence among the younger population, likely due to the increase in obesity rates. ${ }^{1}$ During the 1990s, the average age at OAK diagnosis was 72 years; however, as of 2016, more than half of those with symptomatic OAK were aged younger than 65 years, allowing for substantial time for greater disability to occur. ${ }^{1}$ Of the 14 million people living with OAK in the United States, about 6 million are between the ages of 45 and 64 years and about 6 million are aged 65 years and older. ${ }^{1}$

\section{Patient Burden}

The most common reason for knee replacement surgery is to relieve the pain and disability caused by osteoarthritis, which is predicted to be the fourth-leading cause of disability by the year 2020. ${ }^{8}$ The results of a 2011 study demonstrated that patients with osteoarthritis of the knee or hip have a higher risk of all-cause mortality, which is likely due to concomitant risk factors, including diabetes, cancer, cardiovascular disease, and reduced functional activity levels. ${ }^{9}$ It is evident that proper management strategies are needed for this patient population in order to preserve mobility, maintain and improve patients' quality of life, and reduce the impact of potential diseaserelated comorbidities.

\section{Diagnosis and Treatment Goals}

Diagnosis of OAK involves a clinician assessment of the nature and severity of the pain, often in addition to a measurement of movement in the joint. ${ }^{10}$ Clinicians will often rely on X-rays to 
illustrate knee-narrowing of the joint space, which indicates OAK, and bony spurs. ${ }^{10}$ Magnetic resonance imaging (MRI) is employed in some cases to add clarification and accuracy to the diagnosis. ${ }^{10}$

Following diagnosis, clinicians and patients will work together to determine an appropriate and manageable treatment regimen. Treatment goals generally focus on alleviating OAK-associated pain, increasing range of motion, increasing overall functional strength, and improving physical fitness levels and mobility. ${ }^{10-12}$ Attainment of these treatment goals is often attempted by a combination of nonpharmacological and pharmacological treatment modalities, commonly including acetaminophen, aspirin, and NSAIDs; once these options are exhausted and the condition worsens, surgical options are commonly employed. ${ }^{10-12}$ Nonpharmacological treatment options often include weight reduction, avoiding activities that exert stress on the joint, physical therapy, and rehabilitation. ${ }^{10}$

\section{Treatment Considerations in the Management} of OAK, Including Use of HA Injections

Major treatment guidelines for the pharmacological management of OAK in the United States are published by the American Academy of Orthopaedic Surgeons (AAOS) and the American College of Rheumatology (ACR). ${ }^{13,14}$ Additionally, although not classified as a treatment guideline, the American Medical Society for Sports Medicine (AMSSM) published a scientific statement supporting viscosupplementation injections for OAK in 2015. ${ }^{15}$

The AAOS treatment guidelines recommend oral NSAIDs, topical NSAIDs, or tramadol for the management of symptomatic OAK. ${ }^{13}$ The AAOS notes that it cannot recommend using HA for patients with symptomatic OAK because meta-analyses allowed for its review group to determine that the overall effect of HA did not provide minimum clinically important improvement (MCII) and minimum and minimal clinically important difference (MCID) to patients in this population, using their own interpretation; levels of MCII and MCID are typically defined according to the patient's perceptions of what signifies an important improvement or difference. ${ }^{13}$ For patients with OAK, the ACR recommends the use of acetaminophen, oral NSAIDs, topical NSAIDs, tramadol, or intra-articular corticosteroid injections for initial management. ${ }^{14}$ The ACR indicates that the organization has no recommendations for or against the use of intra-articular hyaluronates as part of a pharmacological regimen for the initial management of OAK; instead, the ACR conditionally recommends the use of HA injections for patients who have had an inadequate response to initial therapy, including corticosteroid injections and oral or topical NSAIDs. ${ }^{14}$

AMSSM noted in its scientific statement that it recommends the use of HA injections in appropriate patients with OAK, citing high-quality evidence demonstrating benefit to patients 60 years of age or older; AMSSM suggests the use of HA injections in patients under the age of 60 years, citing moderate-quality evidence demonstrating benefit in this age group. ${ }^{15}$ Additionally, some providers use HA injections to postpone total knee arthroplasty (TKA) when conservative measures do not relieve symptoms or improve quality of life. TKA is indicated for patients who experience significant, disabling pain caused by advanced arthritis, whose quality of life has significantly been reduced, and whose pain and dysfunction persist despite use of conservative treatment. ${ }^{16}$

\section{Gaps in Care/Guidelines}

While TKA has generally resulted in successful outcomes, satisfaction rates of this surgical invention vary. ${ }^{17-19}$ In a prospective study of patients who underwent TKAs, 39\% of patients reported that the expectations they had regarding the results of the TKA had not been fulfilled, and multiple studies suggest that up to $20 \%$ of patients receiving TKAs are dissatisfied with their results. ${ }^{17-19}$ Despite TKA outcomes not meeting some patients' expectations, the rate of TKA procedures is increasing. One published study projected that by the year 2030, the demand for TKAs is estimated to increase by $673 \%$, to 3.48 million procedures annually. ${ }^{20}$ This projected increase is based on 2003 estimates coupled with the aging population and the desire to maintain an active lifestyle.

The longevity of TKAs is typically greater than 10 years; however, the rate of TKA failures requiring revision varies from $2 \%-5.7 \%$ within the first 5 years to $5 \%-6.8 \%$ within the first 10 years. ${ }^{21-23}$ The rising demand for primary TKAs will inevitably correspond with an increasing demand for revisions of TKAs, and it was projected that demand for revision TKAs would grow by $601 \%$ from 2005 to $2030 .{ }^{20,24}$ The increase in TKAs in combination with dissatisfaction rates, younger age of diagnosis, and rates of TKA revisions point to the need for alternative OAK therapy and management.

\section{Overview of HA Injections and Role in Treatment}

Intra-articular viscosupplementation with the use of $\mathrm{HA}$ injections has been approved by the U.S. Food and Drug Administration (FDA) exclusively for use in treating pain associated with OAK in the United States since 1997. ${ }^{25}$ Per FDA labeling, HA injections are indicated for the treatment of pain in OAK in patients who have failed to respond adequately to conservative nonpharmacologic therapy and simple analgesics (e.g., acetaminophen). Since HA is a natural component of synovial fluids, HA injections replace this substance and restore the protective effect of healthy synovial fluid by increasing the viscosity of synovial fluid in knee joints affected by $\mathrm{OA}$ and potentially reducing and/or counteracting the effects of inflammatory mediators. ${ }^{26} \mathrm{HA}$ injections include avian-/nonavian-based, cross-/noncross-linked, and single/multi-injection formulations. Cross-linking increases the half-life up to 8.8 days, which can increase residence time 
in trace amounts up to 26 weeks. ${ }^{27}$ Additionally, research has evaluated the effect of molecular weight on the effectiveness of HA injections. Low-molecular-weight preparations have been shown to achieve maximum concentration into the joint but have lower elastoviscocity compared with native HA. ${ }^{28}$ Evidence found clinically important reductions in pain with high-molecular-weight formulations, which offer an improved increase in fluid retention into the joint. ${ }^{29}$ In the Panel Insights section of this paper, KOLs' comments are shared regarding the conflicting results of studies that have compared the effectiveness of HA injections with different molecular weights for the treatment of OAK. ${ }^{30-32}$ Adverse events associated with HA injections are minimal and typically limited to injection site pain, joint stiffness, and, possibly, swelling; however, avianbased preparations may potentially elicit more adverse allergic reactions than nonavian-based preparations. ${ }^{33}$

Numerous studies, including observational studies and a few randomized, head-to-head trials, have evaluated the effects of intra-articular HA injections; however, these studies were noted to have poor study design, perceived inherent bias, and lack of consistency. ${ }^{34}$ These poor-quality studies resulted in an inability for guideline-issuing organizations to develop a high-quality meta-analysis necessary for an evidence-based assessment of efficacy. ${ }^{13,14}$ Ong et al. (2016) demonstrated that HA injections were associated with longer time ( 8.7 months) to TKA in patients with OAK..$^{35}$ Another study showed that among patients with OAK, those who received HA injections showed a significantly longer time to TKA compared with those who received none (0.3 years vs. $>1.0$ years, respectively). ${ }^{36}$ The ACR and AAOS treatment guidelines were last updated in 2012 and 2013, respectively. ${ }^{13,14}$

More recently, the AMSSM systematic literature search reported that there are multiple recent randomized controlled trials that indicate that there is evidence to support the use of HA injections for appropriate patients with OAK. ${ }^{15}$ Specifically, the AMSSM recommends HA injections for Kellgren and Lawrence (a classification that is a commonly used clinical tool for the radiographic diagnosis of OAK) grade II-III OAK in patients older than 60 years of age based on high-quality evidence demonstrating clinical benefit. ${ }^{15}$ Due to the treatment response in patients above 60 years of age, the AMSSM also suggests HA injections for patients with OAK who are younger than 60 years of age based on moderate-quality evidence. ${ }^{15}$

Moreover, since HA injections are used as an alternative to corticosteroid injections, viscosupplementation may also minimize the need for corticosteroid injections; corticosteroid injections can cause additional local damage to joint cartilage if used repeatedly long-term or systemic issues such as hyperglycemia in diabetic patients. ${ }^{37,38}$ A 2-year study assessed the impact of intra-articular triamcinolone injections on patients with symptomatic knee osteoarthritis; the results showed significantly greater cartilage volume loss and no significant difference in knee pain in patients receiving triamcinolone injections compared with saline injections. ${ }^{39}$ The results of a trial comparing the safety and efficacy of NSAIDs and HA injections for OAK demonstrated that HA injections are as effective as continuous NSAID use at 5 weeks of treatment and are associated with a more favorable safety profile..$^{40}$ As prolonged NSAID utilization is often associated with gastric complications, ulcers, increased risk for hospitalization, and other adverse effects, HA injections present a safe and equally effective treatment alternative. ${ }^{10,34}$ Additionally, viscosupplementation may offer the benefit of longer duration of effectiveness, with some HA injections offering up to 6 months of relief compared with up to 3 months with the use of corticosteroid injections. ${ }^{25,41-43}$

\section{Panel Insights and Recommendations}

Before the 2013 publication, AAOS treatment guidelines indicated that the AAOS recommendation for or against the use of HA injections in the treatment of OAK was inconclusive. Of note, this recommendation has since been updated to reflect a recommendation against such usage. ${ }^{14}$ However, the AAOS did not determine utility based on OA severity, but rather, osteoarthritis in general. Despite the AAOS and ACR treatment guidelines regarding the use of HA injections in this setting, the panelists' perceptions regarding the utility of HA injections for the management of OAK were aligned with those of the AMSSM, which recommends the use of these products based on previously published studies. The KOLs cited evidence from a clinical study showing HA injections may be most beneficial in earlier grades of OAK, as $91 \%$ and $80 \%$ of patients in radiographic grade I and II OAK, respectively, reported feeling better after injection compared with $76 \%$ and $58 \%$ of patients in grades III and IV, respectively.4. Overall, KOLs perceive HA injections as alternative treatments that may provide their patients with an option to delay TKA.45 Provider KOLs noted that HA injections are an effective alternative to corticosteroid injections as the therapies show equal efficacy in the short term, yet evidence shows HA injections to be superior in duration of pain relief. ${ }^{46}$ KOLs also recommended HA injections be used in patients who experience transient improvement from corticosteroid injections but seek additional relief.

In addition to the discussion regarding the benefits associated with HA injections, KOLs discussed the potential benefits associated with the different formulations of HA products. KOLs referenced evidence in animal studies that suggests that the cross-linking of HA molecules in viscosupplements may increase the half-life of these products, thereby increasing residence time of molecules in the joint space and potentially increasing the production of endogenous hyaluronan in the knee; however, there is some debate regarding the impact of molecular weight on the effectiveness of HA injections. . $7,47-49^{-1}$ KOLs discussed the controversial data that indicate that it is not molecular size-but rather, cross-linking of HA 
molecules-that impacts the effectiveness of these products. Evidence suggests that studies evaluating cross-linked formulations achieved clinically significant reduction in pain in patients with OAK. ${ }^{29}$ The consensus among KOLs was that cross-linking appears to have a benefit in allowing for singleinjection administration rather than the multiple injections required with noncross-linked formulations, and most patients consider single-injection products to be more convenient than multiple-injection products.

\section{Best Practice Considerations}

KOLs identified various considerations that should be defined in order to better indicate HA and properly manage OAK with HA injections. From clinical experience, including private and hospital practice, the 4 provider KOLs concluded that an MRI should not be required to determine a patient's eligibility status for HA injections. Rather, an appropriate radiographic (i.e., weight-bearing film) and clinical evaluation of the grade of $\mathrm{OA}$ is necessary to determine whether a patient is a candidate for treatment with HA injections.

In some cases, providers may choose to perform ultrasoundguided HA injections to increase accuracy and clinical outcomes. KOLs noted that if a patient is morbidly obese and the proper injection site is difficult to locate, an ultrasound may help to ensure the safe and effective administration of the viscosupplement. To prevent the misuse of ultrasound-guided HA injections, KOLs suggested the implementation of a limitation on the use of ultrasound for patients who have a body mass index (BMI) greater than $30 \mathrm{~kg} / \mathrm{m}^{2}$ or who have anatomic variations that render normal landmark-based injection technique a challenge. While KOLs noted that this method may often be an unnecessary precaution, evidence suggests that the enhanced accuracy associated with ultrasound guidance often improves patient-reported clinical outcomes and cost-effectiveness. ${ }^{50}$

The panel also discussed the utility of HA injections, particularly in patients with medical comorbidities. In patients who have comorbidities, especially obesity and diabetes, HA injections may be a more desirable choice than corticosteroid injections due to the corticosteroid-associated risks of additional weight gain and hyperglycemia. ${ }^{38,51}$ Additionally, chronic use of NSAIDs may not be a viable treatment option for some patients due to cardiovascular risk or potential to destabilize blood pressure. ${ }^{52}$ KOLs noted that it may be beneficial for coverage policies to include a list of comorbidities for which HA injections may be an appropriate treatment option; however, the list should be used as a guide, not as a substitute for medical advice, to ensure that a patient-centered treatment selection can still be made.

Following the publication of the 2013 AAOS treatment guidelines, which advised against the use of HA injections for the treatment of OAK, several payers subsequently eliminated coverage of HA products. Of note, Blue Cross Blue Shield of
Kansas City and Blue Cross Blue Shield of Kansas eliminated coverage for viscosupplementation in 2013 and 2014, respectively, and the Society of Actuaries issued a report that identified a nearly 6-fold increase in total knee surgery rates for new enrollees in Kansas during the first quarter of $2014 .{ }^{53}$ While not conclusive, the results of this report may suggest a possible relationship between payers' restrictive coverage policies and the utilization of alternative management strategies, particularly TKA surgical procedures. This may not be the desired outcome payers seek, as TKAs are associated with significantly higher costs compared with HA injections. ${ }^{54}$ As of 2016, Blue Cross Blue Shield of Kansas still considers HA injections not medically necessary, citing evidence that suggested larger treatment effects in small trials than in large-scale trials, and concluding that there is a lack of definitive treatment benefit. ${ }^{54}$ In response to this issue, the panelists referenced the 2015 data released by the Osteoarthritis Research Society International, which confirms that treatment with HA injections can result in a delay in the need for TKA by up to 3.6 years..$^{55} \mathrm{KOLs}$ noted that delaying the need for TKA in patients for a number of years may result in fewer revision TKAs and costly complications throughout the course of the patient's lifetime, and such delays have the potential to result in substantial cost savings for payers

KOLs pointed to evidence demonstrating that $\mathrm{HA}$ injections offer a cost-effective alternative in the management of OAK. ${ }^{56,57}$ A 2014 analysis used analytic models to compare HA treatments with corticosteroid treatments, and the results indicated that HA was both less costly and more effective than corticosteroids with NSAIDs and analgesics and is the dominant treatment strategy. ${ }^{57}$ Studies comparing cost outcomes of HA injections to conventional care, including analgesics, NSAIDs, and assistive devices, showed that HA injections were shown to be a cost-effective treatment strategy. ${ }^{56,57}$

Regarding product preference, provider KOLs referenced the barrier they currently face with highly restricted or nonexistent access to HA injectable products. Although some providers indicated that they have specific agents they prefer to use in practice, the panelists emphasized that having access to any high-molecular-weight HA injectable products was preferable to having no access. If access must be restricted to one product type, the panelists leaned toward single-injection products. The rationale for preferring single-injection products is because patients prefer fewer injections and value the convenience of a single office visit as opposed to multiple visits. Additionally, concerning avian-based and nonavian-based products, providers noted that aside from potential allergic reactions to avian-based preparations, there is no significant difference in overall clinical effectiveness; however, payer KOLs suggested that the formulary should include access to both product types, especially where patients have allergies or sensitivity to certain products. ${ }^{33} \mathrm{~A}$ study showed that while both avian- and 
nonavian-based products improved pain in patients with OAK, a significantly greater number of adverse events was observed in patients treated with avian HA products. ${ }^{58}$

\section{Future Needs and Considerations}

In the future, it would be beneficial to have prospective, controlled studies to establish the effectiveness of HA injections as a treatment option for OAK and additional comparative studies for the various types of HA products. Both types of studies may be of value in treatment selection and coverage decisionmaking processes for providers and payers. Additionally, there may be an opportunity for patient education surrounding the benefits and risks associated with HA products for the treatment of OAK to allow for a well-informed treatment decisionmaking process and clinical algorithm. The lack of information and product inaccessibility may contribute to suboptimal management of OAK or patient requests for earlier TKA.

The development of a comprehensive policy that permits the coverage of at least 1 avian-based, cross-linked, single-injection formulation and 1 nonavian-based, multi-injection HA product for candidates may benefit both payers and patients. The policy should incorporate a mechanism (i.e., exceptions request process) by which providers can request a nonpreferred product based on individual patient clinical presentation and response to prior therapies. This policy should also allow for the transition between covered products to account for potential suboptimal responses to other viscosupplementation products. The policy should include certain coverage criteria, such as a list of comorbidities for which the use of HA injections is preferable, an age range age for which coverage is permitted, and a minimum BMI requirement for the use of ultrasound-guided HA injections. In conclusion, the provider and payer panelists agree with the conclusions of the AMSSM regarding the advantages of HA injections in patients with OAK and recommend the inclusion of HA injections on the formularies of managed care organizations.

\section{Authors}

JACK BERT, MD, University of Minnesota School of Medicine, Minneapolis; JIM KENNEY, RPh, MBA, Harvard Pilgrim Healthcare, Wellesley, Massachusetts; NICHOLAS A. SGAGLIONE, MD, Northwell Health Orthopaedics, Great Neck, New York; SCOTT MCCLELLAND, PharmD, RPh, CHIE, Florida Blue, Jacksonville; ROBERT BROPHY, MD, Washington University School of Medicine, St. Louis, Missouri; JOHN TOTH, RPh, Yale Health, New Haven, Connecticut; JOSEPH RUANE, DO, McConnell Spine, Sport, and Joint Center, Columbus, Ohio, and Ohio University College of Osteopathic Medicine, Athens; YOUSAF ALI, MD, FACR, Icahn School of Medicine at Mt. Sinai, New York, New York; SHEILA ARQUETTE, RPh, Independent Health, Buffalo, New York; VINOD DASA, MD, Louisiana State University Health Sciences Center, New Orleans; Oschner Kenner Medical Center, Kenner, Louisiana; Vector Medical, Boca Raton, Florida; and Touro University Nevada College of Osteopathic Medicine, Henderson, Nevada; and MARIA LOPES, MD, Magellan Rx Management.

CORRESPONDENCE: Lindsay Speicher, JD, Magellan Rx Management, 88 Silva Ln., Tech 4, Middletown, RI 02842. Tel.: 401.344.1105; E-mail: Ispeicher@magellanhealth.com.

\section{DISCLOSURES}

This panel discussion and report was facilitated by Magellan Rx Manage-ment and funded by Sanofi. Bert and Ruane report fees from Sanofi outside of this project. Sgaglione reports royalty payments from Zimmer Biomet and Wolters Kluwer. Dasa has received fees from Bioventus and Myoscience. All the authors received an honorarium for work on this project. Lopes is employed by Magellan Rx Management.

\section{REFERENCES}

1. Deshpande BR, Katz JN, Solomon DH, et al. Number of persons with symptomatic knee osteoarthritis in the U.S.: impact of race and ethnicity, age, sex, and obesity. Arthritis Care Res (Hoboken). 2016;68(12):1743-50.

2. Arthritis Research UK. What are the symptoms of osteoarthritis of the knee? Available at: http://www.arthritisresearchuk.org/arthritis-information/ conditions/osteoarthritis-of-the-knee/symptoms.aspx. Accessed May 15, 2018.

3. Heijink A. Biomechanical considerations in the pathogenesis of osteoarthritis of the knee. Knee Surg Sports Traumatol Arthosc. 2012;20(3):423-35.

4. Altman RD. Status of hyaluronan supplementation therapy in osteoarthritis. Curr Rheumatol Rep. 2003;5(1):7-14

5. Kalaci A, Yilmaz HR, Aslan B, Sögüt S, Yanat AN, Uz E. Effects of hyaluronan on nitric oxide levels and superoxide dismutase activities in synovial fluid in knee osteoarthritis. Clin Rheumatol. 2007;26(8):1306-11.

6. Moreland LW. Intra-articular hyaluronan (hyaluronic acid) and hylans for the treatment of osteoarthritis: mechanisms of action. Arthritis Res Ther. 2003;5(2):54-67.

7. Gower T. Hyaluronic acid injections for osteoarthritis. Arthritis Foundation. Available at: http://www.arthritis.org/living-with-arthritis/ treatments/medication/drug-types/other/hyaluronic-acid-injections.php. Accessed May 15, 2018.

8. Woolf AD, Pfleger B. Burden of major musculoskeletal conditions. Bull World Health Org. 2003;81(9):646-56. 
9. Nuesch E, Dieppe P, Reichenbach S, Williams S, Iff S, Jüni P. All cause and disease specific mortality in patients with knee or hip osteoarthritis: population based cohort study. BMJ. 2011;342:d1165.

10. Bhatia D, Bejarano T, Novo M. Current interventions in the management of knee osteoarthritis. J Pharm Bioallied Sci. 2013;5(1):30-38

11. Lozada CJ, Culpepper SJ. Osteoarthritis treatment \& management. Available at: http://emedicine.medscape.com/article/330487-treatment\#dl. Accessed May 15, 2018.

12. Zhang W, Moskowitz RW, Nuki G, et al. OARSI recommendations for the management of hip and knee osteoarthritis, part II; OARSI evidence-based, expert consensus guidelines. Osteoarthritis Cartilage. 2008;16(2):137-62.

13. American Academy of Orthopaedic Surgeons. Treatment of osteoarthritis of the knee. Available at: https://www.aaos.org/research/guidelines/ TreatmentofOsteoarthritisoftheKneeGuideline.pdf. Accessed May 15, 2018.

14. Hochberg MC, Altman RD, April KT, et al. American College of Rheumatology 2012 recommendations for the use of nonpharmacologic and pharmacologic therapies in osteoarthritis of the hand, hip, and knee. Arthritis Care Res. 2012;64(4):465-74.

15. Trojian TH, Concoff AL, Joy SM, Hatzenbuehler JR, Saulsberry WJ, Coleman CI. AMSSM scientific statement concerning viscosupplementation injections for knee osteoarthritis: importance for individual patient outcomes. Clin J Sport Med. 2016;26(1):1-11.

16. Palmer SH. Total knee arthroplasty. Available at: http://emedicine.medscape.com/article/1250275-overview\#a2. Accessed May 15, 2018

17. Suda AJ, Seeger JB, Bitsch RG, Krueger M, Clarius M. Are patients' expectations of hip and knee arthroplasty fulfilled? A prospective study of 130 patients. Orthopedics. 2010;33(2):76-80

18. Bourne RB, Chesworth BM, Davis AM, Mahomed NN, Charron KD. Patient satisfaction after total knee arthroplasty: who is satisfied and who is not? Clin Orthop Relat Res. 2010;468(1):57-63.

19. Noble PC, Conditt MA, Cook KF, Mathis KB. The John Insall Award: patient expectations affect satisfaction with total knee arthroplasty. Clin Orthop Relat Res. 2006;452:35-43.

20. Kurtz S, Ong K, Lau E, Mowat F, Halpern M. Projections of primary and revision hip and knee arthroplasty in the United States from 2005 to 2030. J Bone Joint Surg Am. 2007;89(4):780-85.

21. Khan M, Osman K, Green G, et al. The epidemiology of failure in total knee arthroplasty. Bone Joint J. 2016;98-B(1 Supp A):105-12.

22. Bass AR, McHugh K, Fields K, et al. Higher total knee arthroplasty revision rates among United States blacks than white: a systematic literature review and meta-analysis. J Bone Joint Surg Am. 2016;98(24):2103-08.

23. Motififard M, Pesteh M, Etamadifar MR, et al. Causes and rates of revision total knee arthroplasty: local results from Isafan, Iran. Adv Biomed Res. 2015;4:111.

24. Jasper LL, Jones CA, Mollins J, et al. Risk factors for revision of total knee arthroplasty: a scoping review. BMC Musculoskelet Disord. 2016;17:182.

25. Sun S, Chou YJ, Hsu CW, Chen WL. Hyaluronic acid as a treatment for ankle osteoarthritis. Curr Rev Musculoskelet Med. 2009;2(2):78-82.

26. Thomas T, Amouroux F, Vincent P. Intra articular hyaluronic acid in the management of knee osteoarthritis: pharmaco-economic study from the perspective of the national health insurance system. PLoS One. 2017;12(3):e0173683.

27. Altman RD, Akermark C, Beaulieu A, Schnitzer T; Durolane International Study Group. Efficacy and safety of a single intra-articular injection of non-animal stabilized hyaluronic acid (NASHA) in patients with osteoarthritis of the knee. Osteoarthritis Cartilage. 2004;12(8):642-49.

28. Bagga H, Burkhardt D, Sambrook P, March L. Longterm effects of intraarticular hyaluronan on synovial fluid on osteoarthritis of the knee.

J Rheumatol. 2006;33(5):946-50.

29. Johal H, Devji T, Schemitsch EH, Bhandari M. Viscosupplementation in knee osteoarthritis: evidence revisited. JBJS Reviews. 2016;4(4):ell-ell1.
30. Bannuru RR, Natov NS, Dasi UR, Schmid CH, McAlindon TE. Therapeutic trajectory following intra-articular hyaluronic acid injection in knee osteoarthritismeta-analysis. Osteoarthritis Cartilage. 2011;19(6):611-19.

31. Rutjes AW, Juni P, da Costa BR, Trelle S, Nuesch E, Reichenbach S. Viscosupplementation for osteoarthritis of the knee: a systematic review and metaanalysis. Ann Intern Med. 2012;157:180-91.

32. Sun SF, Hsu CW, Hwang CW, et al. Hyaluronate improves pain, physical function, and balance in the geriatric osteoarthritic knee: a 6-month follow-up study using clinical tests. Osteoarthritis Cartilage. 2006;14:696-701.

33. Bhadra AK, Altman RD, Dasa V. Appropriate use criteria for hyaluronic acid in the treatment of knee osteoarthritis in the United States. Cartilage. 2017;8(3):234-54.

34. McArthur BA, Dy CJ, Fabricant PD, Gonzalez Della Valle A. Long term safety, efficacy, and patient acceptability of hyaluronic acid injection in patients with painful osteoarthritis of the knee. Patient Prefer Adherence. 2012;6:905-10.

35. Ong KL, Anderson AF, Niazi F, et al. Hyaluronic acid injections in Medicare knee osteroarthritis patients are associated with longer time to knee arthroplasty. J Arthroplasty. 2016;31(8):1667-73.

36. Altman R, Lim S, Steen RG, Dasa V. Hyaluronic acid injections are associated with delay of total knee replacement surgery in patients with knee osteoarthritis: evidence from a larger U.S. health claims database. PLoS One. 2016;11(1):e0148591.

37. Wernecke C, Braun HJ, Dragoo JL. The effect of intra-articular corticosteroids on articular cartilage: a systematic review. Orthop J Sports Med. 2015;3(5):2325967115581163.

38. Habib G, Safia A. The effect of intra-articular injection of betamethasone acetate/betamethasone sodium phosphate on blood glucose levels in controlled diabetic patients with symptomatic osteoarthritis of the knee. Clin Rheumatol. 2009;28(1):85-87.

39. McAlindon TE, LaValley MP, Harvey WF, et al. Effect of intra-articular triamcinolone vs. saline on knee cartilage volume and pain in patients with knee osteoarthritis: a randomized clinical trial. JAMA. 2017;317(19):1967-75.

40. Ishijima M, Nakamura T, Shimizu K, et al. Intra-articular hyaluronic acid injection versus oral non-steroidal anti-inflammatory drug for the treatment of knee osteoarthritis: a multi-center, randomized, open-label, non-inferiority trial. Arthritis Res Ther. 2014;16(1):R18.

41. Foster ZJ, Voss TT, Hatch J, Frimodig A. Corticosteroid injections for common musculoskeletal conditions. Am Fam Physician. 2015;92(8):694-99.

42. Morelli J. Use of corticosteroids in osteoarthritis. Available at: http://www. arthritis.org/living-with-arthritis/treatments/medication/drug-types/corticosteroids/corticosteroid-injections.php. Accessed May 15, 2018.

43. Roskos SE. Intra-articular corticosteroid for treating osteoarthritis of the knee. Am Fam Physician. 2005;72(7):1222-24.

44. Lussier A, Cividino AA, McFarlane CA, et al. Viscosupplementation with hylan for the treatment of osteoarthritis: findings from clinical practice in Canada. J Rheumatol. 1996;23(9):1579-85.

45. Waddell DD, Joseph B. Delayed totally knee replacement with Hylan G-F 20. J Knee Surg. 2016;29(2):159-68.

46. Askari A, Gholami T, NaghiZadeh MM, et al. Hyaluronic acid compared with corticosteroid injections for the treatment of osteoarthritis of the knee: a randomized control trial. Springerplus. 2016;5:442.

47. Wen DY. Intra-articular hyaluronic acid injections for knee osteoarthritis. Am Fam Physician. 2000;62(3):565-70.

48. Jackson DW, Simon TM. Intra-articular distribution and residence time of Hylan A and B: a study in the goat knee. Osteoarthritis Cartilage. 2006;14(12):1248-57.

49. Lee PB, Kim YC, Lim YJ, et al. Comparison between high and low molecular weight hyaluronates in knee osteoarthritis patients: open-label, randomized, multi-centre clinical trial. J Int Med Res. 2006;34(1):77-87.

50. Berkoff DJ, Miller LE, Block JE. Clinical utility of ultrasound guidance for intra-articular knee injections: a review. Clin Interv Aging. 2012;7:89-95. 
51. Liu D, Ahmet A, Ward L, et al. A practical guide to the monitoring and management of the complications of systemic corticosteroid therapy. Allergy Asthma Clin Immunol. 2013;9(1):30.

52. Varga Z, Rafay ali Sabzwari S, Vargova V. Cardiovascular risk of nonsteroidal anti-inflammatory drugs: an under-recognized public health issue. Cureus. 2017;9(4):e1144.

53. Young R. Did BCBS cause a 500\% leap in total knee surgery rates? Available at: https://ryortho.com/2015/06/did-bcbs-cause-a-500-leap-intotal-knee-surgery-rates/. Accessed May 15, 2018.

54. BCBS of Kansas. Intra-articular hyaluronan injections for osteoarthritis. Available at: https://www.bcbsks.com/customerservice/Providers/ MedicalPolicies/policies/policies/Intra-ArticularHyaluronanInjections_ Osteoarthritis_2017-12-29.pdf. Accessed May 15, 2018.
55. Altman R, Lim S, Steen RG, Dasa V. Hyaluronic acid injections are associated with delay of total knee replacement surgery in patients with knee osteoarthritis: evidence from a large U.S. health claims database. PLoS One. 2015;10(12):e0145776.

56. Rosen J, Sancheti P, Fierlinger A, et al. Cost-effectiveness of different forms of intra-articular injections for the treatment of osteoarthritis of the knee. Adv Ther. 2016;33:998-1011.

57. Hatoum H, Fierlinger AL, Lin-SJ, et al. Cost-effectiveness analysis of intra-articular injections of a high molecular weight bioengineered hyaluronic acid for the treatment of osteoarthritis knee pain. J Med Econ. 2014;17(5):1-12

58. Petrella R, Cogliano A, Decaria J. Comparison of avian and nonavian hyaluronic acid in osteoarthritis of the knee. Orthopedic Res Rev. 2010;2:5-9. 


\section{Supplement}

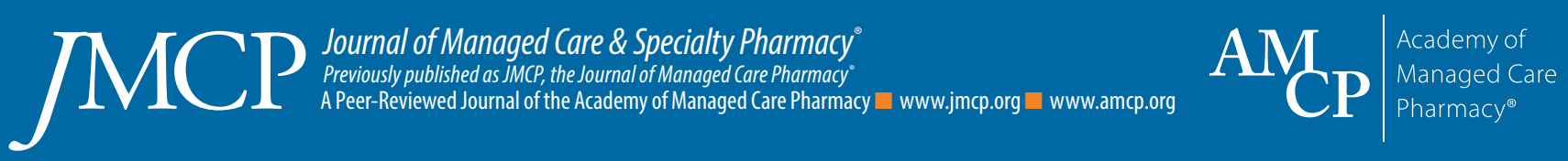

